\title{
Constipação intestinal funcional
}

Flávio Antonio Quílici

Lisandra Carolina Marques Quílici

\section{INTRODUÇÃO}

Desde o Egito antigo se atribui grande importância ao funcionamento regular do intestino. A constipação intestinal funcional, em geral, não é uma doença, mas um sintoma que pode estar associado com doenças orgânicas, digestivas ou extradigestivas. É a segunda queixa gastroenterológica mais autorrelatada, mas não há dados epidemiológicos da sua prevalência no Brasil. Segundo várias publicações, ela ocorre em aproximadamente $20 \%$ da população ocidental, sendo mais presente em mulheres, crianças, idosos e nos indivíduos de menor poder econômico.

A dificuldade para se conceituar a constipação intestinal se deve, principalmente, à diferença entre a opinião do paciente e como ela é entendida do ponto de vista médico.

Segundo os critérios do ROMA IV, o conceito de constipação intestinal funcional deve incluir dois ou mais dos seguintes itens:

- Esforço evacuatório durante pelo menos 25\% das evacuações.

- Fezes grumosas ou duras em pelo menos $25 \%$ das evacuações.

- Sensação de evacuação incompleta em pelo menos $25 \%$ das evacuações.

- Sensação de obstrução ou bloqueio anorretal em pelo menos 25\% das evacuações.

- Manobras manuais para facilitar pelo menos 25\% das evacuações (p. ex., auxílio digital, compressão do assoalho pélvico).

- Menos de três evacuações por semana. 
A classificação mais utilizada na prática médica é:

- Constipação intestinal funcional ou primária.

- Constipação intestinal orgânica ou secundária.

Na maioria dos casos, a constipação intestinal é funcional e produzida por distúrbios motores do cólon e/ou reto, apresenta ausência de alterações anatômicas, tem natureza bioquímica ou metabólica e não tem relação com doenças neuromusculares intestinais ou sistêmicas. Ela está relacionada à anormalidade do esvaziamento colorretal e incide preferencialmente na população jovem, com início mal demarcado, evolução insidiosa, lentamente progressiva, longa duração, não comprometendo o doente no seu estado geral e nutricional.

\section{MECANISMOS DA CONSTIPAÇÃO INTESTINAL FUNCIONAL}

As principais causas da constipação intestinal funcional são: alimentação inadequada, sedentarismo, alteração do reflexo da evacuação e posição incorreta no ato da defecação.

Os fatores dietéticos e comportamentais são considerados os maiores responsáveis pelo número significativo de constipados funcionais entre as populações ocidentais, particularmente as dos grandes centros urbanos.

O menor consumo de vegetais e leguminosas (capazes de fornecer um bom resíduo para a formação do bolo fecal) aliado à sua substituição por produtos absorvíveis tem o impacto de comprometer o volume das fezes e, por consequência, o estímulo para a evacuação.

O reflexo da evacuação (sensação retal da vontade de evacuar) para a maioria dos indivíduos costuma ocorrer no mesmo horário, próximo ou não da alimentação. O indivíduo constipado, em geral, reprime o reflexo evacuatório voluntariamente, por ocupações profissionais ou sociais. A repressão desse reflexo, com frequência, acompanha-se da perda progressiva da sensibilidade do reto à sua distensão pelo bolo fecal, chegando a desaparecer por completo.

A postura física durante a evacuação é fundamental para a utilização de todo potencial muscular abdominal para promover a completa expulsão das fezes. A função de alavanca das pernas com seu apoio no chão produz melhor condição para a flexão do tronco sobre o abdome, permitindo que se obtenha o máximo do rendimento dessa musculatura.

Outro fatos que contribuem para a constipação funcional:

- A desconcentração durante o ato da evacuação. Muitos indivíduos acabam utilizando esse momento para leitura, rever suas agendas de trabalho ou 
compromissos, fumar, fazer telefonemas, enfim, ficam distantes da efetiva participação nos mecanismos voluntários da evacuação.

- A idade avançada é responsável pela maior incidência da constipação por causa da menor sensibilidade e motricidade intestinais, agravada ainda mais pelo sedentarismo.

- O abuso de laxativos de ação irritante também é uma das causas que se associa à constipação intestinal funcional. Sua eficácia inicial encobre um aumento progressivo da espasticidade do cólon, exigindo doses crescentes do medicamento e terminando no retorno da dificuldade de evacuar na mesma intensidade que originou sua utilização.

- Os laxantes compostos por produtos naturais (fitoterápicos), de elevado consumo leigo, são muito usados na suposição de sua inocuidade. No entanto, alguns atuam por irritação, estimulando as terminações nervosas dos plexos intestinais, levando, por uso prolongado, à sua dessensibilização, por vezes de forma irreversível.

\section{ABORDAGEM CLÍNICA}

\section{História clínica}

A maioria dos doentes, ao consultar o especialista a respeito de sua constipação, provavelmente já se submeteu a múltiplas tentativas para corrigi-la, por intermédio de automedicação, medidas caseiras ou por prescrição de outros médicos, sem atingir o resultado esperado. Como em qualquer atendimento, o diagnóstico inicia-se por uma detalhada história clínica, a partir da queixa principal. É absolutamente necessário que todas as características das evacuações e do bolo fecal sejam interrogadas, mesmo que não informadas espontaneamente.

É importante conhecer, para fins de comparação, o ritmo intestinal prévio ao início da constipação. A constipação funcional costuma ser de longa evolução e benigna e praticamente guarda as mesmas características desde sua instalação, independentemente da duração, ao contrário da constipação de aparecimento recente que é mais suspeita de ter causa orgânica.

Deve-se identificar mudanças no estilo de vida do paciente que possam ter coincidido com a modificação do hábito intestinal, como trocas de horário ou tipo de trabalho, mudança da alimentação etc. Avalia-se a atividade física costumeira e a existência do reflexo da evacuação.

Sobre o ato da evacuação é preciso pesquisar sua frequência, qual o grau de esforço para realizá-la, volume aproximado eliminado, sensação de esvaziamento retal completo ou não, calibre ou formato das fezes (escala de Bristol) e 
se há associação de outros sintomas, como dor anal e/ou abdominal, distensão, flatulência, sintomas digestivos altos etc.

São considerados sinais de alarme e devem ser rigorosamente investigados: febre, emagrecimento, sangramento, muco e presença de restos alimentares íntegros eliminados com o bolo fecal.

Esforço intenso, prolongado, mesmo para fezes não endurecidas, sugere a possibilidade de evacuação obstruída. Manobras de pressão externa sobre o períneo ou a vagina ou digitais para remoção das fezes do canal anal têm a mesma conotação.

É fundamental indagar o paciente sobre o consumo de medicamentos rotineiros, prescritos ou de uso voluntário, incluindo laxativos e doses utilizadas, bem como obter informações sobre doenças prévias conhecidas que tenham alguma relação com o ritmo intestinal e com intervenções cirúrgicas envolvendo a cavidade abdominal e suas estruturas, além de eventuais queixas orificiais e perineais.

Deve-se interrogar o paciente ainda sobre doenças pulmonares restritivas, distúrbios neurológicos pregressos ou atuais, alterações metabólicas, particularmente relacionadas a diabetes ou sintomas e sinais que sugiram hipotireoidismo, hipercalcemia, mudanças do desempenho muscular geral e da função renal.

Nos antecedentes familiares, histórico de neoplasia colorretal deve ser aceito como sinal de alarme.

\section{Exame físico}

Os achados propedêuticos dependem da etiologia da constipação. Nos pacientes com o tipo funcional, o exame físico em geral é normal. Cabe, entretanto, atenção ao estado geral do doente, devendo-se investigar presença de anemia e/ou desnutrição, alterações pulmonares, cardiocirculatórias ou neuromusculares, sinais de disfunção tireoidiana, hipotensão postural etc. No exame abdominal pode haver, quando muito, certa sensibilidade à palpação, especialmente dos segmentos do cólon, sendo possível avaliar seu calibre, um sinal indireto do grau de sua espasticidade ou dilatação. Os achados de aumento de volume abdominal e de vísceras, a presença de movimentos peristálticos visíveis, ascite, cicatrizes cirúrgicas e massas suspeitas devem remeter ao diagnóstico de doença orgânica e sua investigação se impõe. A avaliação das condições neuromusculares, ainda que simplificada, é recomendada.

O exame proctológico é um procedimento indispensável do exame físico do doente constipado, pois pode contribuir com informações para sua abordagem, particularmente nos pacientes cujo histórico sugira a hipótese de evacuação obstruída. 


\section{Diagnóstico}

$\mathrm{Na}$ grande maioria dos casos será possível, com a história e o exame físico completo, concluir pelo diagnóstico clínico da constipação intestinal funcional. Lembrar que muitos dos constipados, com simples correções higienodietéticas, evoluem com normalização do seu ritmo intestinal, sem necessidade de qualquer investigação complementar. Parte deles, entretanto, apresentará sintomas mais graves compatíveis com inércia colônica, evacuação obstruída, ou ambos. Outros terão seu diagnóstico suspeito ou efetivamente apoiado no conhecimento prévio de obstruções mecânicas, ou ainda secundárias a doenças sistêmicas. Um contingente significativo de doentes com queixa de constipação tem, na verdade, sintomas que, no conjunto, são representativos da síndrome do intestino irritável da forma constipada, sendo necessário lembrar-se desse diagnóstico diferencial, pois requer orientações e condições terapêuticas particulares.

\section{INVESTIGAÇÃO COMPLEMENTAR}

\section{Abordagem laboratorial}

Poucos procedimentos são necessários para os doentes que devem ter seu diagnóstico etiológico investigado. Avaliações sobre anemia e estado nutricional são obtidas por meio do hemograma e da dosagem de proteínas séricas. Testes para análise de possíveis alterações endócrinas ou metabólicas, fazendo parte de doenças subjacentes ou insuspeitas, recomendam as dosagens sanguíneas de glicose, creatinina, potássio, cálcio e fósforo, $\mathrm{T}_{4}$ e TSH, sempre correlacionadas com os parâmetros clínicos. Outras investigações ficam reservadas para situações menos comuns ou sugeridas pelos resultados dessa primeira etapa laboratorial.

\section{Colonoscopia/enema opaco}

Têm sua indicação decidida de acordo com a suspeita clínica. Se a finalidade é pesquisar mudanças anatômicas como dilatações e/ou alongamentos de segmentos colorretais, o procedimento radiológico deve ser o preferido, pois essas anormalidades escapam da observação e do diagnóstico do endoscopista. A colonoscopia tem menor indicação no estudo da constipação intestinal que o comentado para o exame radiológico dos cólons e deve complementar a investigação para esclarecimento do mau funcionamento intestinal, exclusivamente, quando lesões detectadas previamente na radiografia contrastada deixam dúvidas sobre sua natureza. O diagnóstico diferencial com o câncer de cólon, especialmente nos doentes com constipação de início recente ou com si- 
nais de alarme, pode ser necessário. Seria desejável que, no atendimento desses pacientes, o médico utilizasse seu senso crítico da melhor forma possível, para decidir o benefício de uma investigação na conduta de cada caso.

\section{Tempo de trânsito colônico}

O método dos marcadores radiopacos tem custo relativamente pequeno e exposição radiológica mínima, podendo fazer parte da investigação do diagnóstico diferencial da constipação intestinal em qualquer local, mesmo no de recursos menores. O teste é constituído por pequenos elementos sólidos de material inerte, de diferentes formatos, em número de 20 ou 25, contidos em uma cápsula do tipo usado para fins farmacêuticos e ingerida por via oral. Após sua desintegração gástrica, liberam-se os marcadores, que farão todo o percurso intestinal, sendo eliminados no bolo fecal sem modificação. Radiografias simples do abdome seguirão seu deslocamento, havendo um tempo fisiológico estabelecido para a eliminação parcial ou total dos elementos radiopacos pelas fezes. Sua contagem e localização definirão, com razoável precisão, a lentidão da motricidade do cólon, inclusive permitindo a demarcação das regiões nas quais o trânsito é feito com dificuldade. Desde que a atividade motora do cólon seja normal, $80 \%$ ou mais dos marcadores identificados radiograficamente devem, no $5^{\circ}$ dia após sua ingestão, ter sido evacuados ou pelo menos ter atingido o reto. Considera-se inércia colônica quando um número superior a $20 \%$ dos marcadores permanece retido nos segmentos proximais e mediais do cólon no $5^{\circ}$ dia após sua administração. Nos doentes que apresentam disfunção do assoalho pélvico, a retenção se localiza na região reto-anal. O método também é usado para identificar os casos de constipação imaginária, uma entidade clínica talvez não tão rara quanto possa a princípio parecer. Obviamente, durante os dias desse teste não é permitida a utilização de qualquer droga que atue sobre a motricidade intestinal.

A cintilografia também pode ser utilizada para avaliação do trânsito colônico, com a utilização de cápsulas com invólucro $\mathrm{pH}$-dependente contendo no seu interior o preparado radioativo, $\operatorname{In}^{111}$ ou $\mathrm{Tc}^{99}$, resistentes à passagem pelo estômago e intestino delgado e que se dissolvem em meio alcalino, encontrado no íleo distal, não necessitando assim de qualquer preparo do cólon.

\section{Abordagem radiológica}

$\mathrm{Na}$ fase geral da investigação, a radiografia simples de abdome para uma primeira análise da provável retenção de fezes, em relação à sua quantidade e distribuição, tem seu valor no reconhecimento inicial do grau e das caracte- 
rísticas topográficas do armazenamento do bolo fecal. Quando o acúmulo for predominantemente proximal e não houver causas que expliquem esse erro de deslocamento, inércia do cólon passa a ser a maior suspeita etiológica. Caso esse fato ocorra preferencialmente no sigmoide e no reto, os testes seguintes se orientarão para o diagnóstico de evacuação obstruída. A víscera inteiramente ocupada por fezes levará a hipótese para a associação entre as duas disfunções ou para doenças orgânicas. O estudo do cólon por exames de imagem acaba sendo a sequência natural na investigação da constipação intestinal.

\section{Tempo de trânsito do intestino delgado}

A medida do tempo de trânsito do intestino delgado não faz parte dos protocolos habituais de investigação nos casos de constipação intestinal funcional.

\section{Métodos de avaliação anorretal}

Estudar a evacuação retal é importante nos portadores de constipação crônica, cuja etiologia não tenha sido diagnosticada nos distúrbios motores do intestino delgado e/ou cólon. A função evacuatória poderá ser abordada por métodos radiológicos ou cintilográficos.

\section{Defecografia}

A videodefecografia, associada ao enema opaco convencional, completa o estudo anatômico do cólon com a avaliação funcional do segmento anorretal, ambos em um só tempo. Sua aplicabilidade clínica na identificação de disfunções do ato de evacuar deveria recomendá-la rotineiramente. Os aspectos mais relevantes dessa técnica são a constatação por imagem dinâmica:

- Da não angulação da transição reto-anal, dificultada pela não retificação do canal anal durante o esforço da evacuação.

- Do comprometimento da descida do assoalho pélvico, relacionado à contratura do músculo puborretal.

- Da identificação de prolapsos, retoceles, enteroceles e intussuscepção reto-anal. Ainda que a defecografia possa auxiliar no diagnóstico da dinâmica da evacuação final, não deve ser indicada de rotina a não ser na suspeita de defecação obstruída.

\section{Ultrassonografia e ressonância magnética}

Embora, a radiologia convencional e a medicina nuclear venham respondendo a maioria das questões envolvendo o estudo das disfunções anorretais 
e perineais relacionadas com a evacuação obstruída, alguns métodos de imagem, mais recentemente introduzidos na prática médica, têm estimulado os pesquisadores no desenvolvimento de novos procedimentos diagnósticos da constipação intestinal. Além da ultrassonografia (USG) transperineal, a ressonância magnética (RM) com avaliação da região pélvica e endoanal se apresenta como uma modalidade alternativa simples, não ionizante e minimamente invasiva para o estudo da anatomia e da função do assoalho pélvico.

\section{Avaliação dinâmica neuromuscular anorretal}

As estruturas neuromusculares envolvidas na eliminação do conteúdo anorretal podem ter sua função avaliada por meio de alguns testes recomendados nos pacientes com constipação secundária a alterações motoras dos segmentos distais do intestino grosso e/ou perineais.

\section{Manometria anorretal}

É o teste mais utilizado para avaliação da função anorretal motora, cuja alteração pode ocorrer nos dois sentidos, da incontinência à constipação. Fornece informações sobre o desempenho esfincteriano, o reflexo autonômico e a sensibilidade retal.

\section{Expulsão do balão}

O teste pretende analisar a função motora e a coordenação do reto. Indivíduos normais são capazes de expulsar um balão intrarretal contendo desde $50 \mathrm{~mL}$ até $150 \mathrm{~mL}$ de água. Doentes constipados com ou sem trânsito lento e os portadores de megarretos não conseguem eliminá-lo, mesmo sob esforço, ainda que a pressão nesse segmento alcance valores semelhantes aos controles. Essa situação levanta as hipóteses de obstrução mecânica ou de total falta de relaxamento esfincteriano.

\section{Eletromiografia}

A medida da atividade elétrica do assoalho pélvico pela eletromiografia é mais um complemento de avaliação do seu funcionamento, válido também para análise do desempenho do esfíncter anal externo. Eletrodos identificam o movimento esfincteriano durante o ato de evacuar, podendo ser o método de escolha no estudo da evacuação obstruída. Contudo, a maior indicação da eletromiografia é na pesquisa da atividade funcional da musculatura do assoalho pélvico, durante sua contração voluntária, na tosse e no ato da evacuação. Como é um procedimento que integra o estímulo neurológico e a resposta muscular, seus dados permitem o diagnóstico de danos de ambos os sistemas. 


\section{TRATAMENTO CLÍNICO}

Na maioria das vezes, medidas gerais, higienodietéticas e comportamentais serão suficientes para a correção da constipação funcional. Antes de qualquer orientação cabe ao médico informar o paciente, em terminologia simples, sobre os mecanismos da evacuação intestinal e os fatores nela envolvidos. Essa atenção será sempre útil para a compreensão de possíveis falhas e de medidas do seu acerto que permitam contar com sua colaboração.

\section{Dieta}

Na história clínica sobre hábitos alimentares é feito um balanço aproximado da quantidade de fibras e de líquidos ingeridos diariamente. Correções, se necessárias, devem ser propostas, respeitando-se condições individuais de paladar, horários disponíveis para refeições etc. Restrições pessoais em termos de alimentos podem exigir suplementação por preparados comerciais com propriedades semelhantes, ou seja, de aumento do volume fecal por retenção de água. A insistência para o consumo de líquidos é importante, no mínimo $1,5 \mathrm{~L} /$ dia.

Reconhecidamente, uma adequada ingestão de fibras é capital no tratamento da constipação. Seu insucesso pode estar relacionado a uma baixa prescrição por parte do médico ou por relutância do doente, em razão do desconforto que ocasionam se introduzidas em grande quantidade ou rapidamente. Elas estão presentes em uma grande variedade de plantas e alimentos, vegetais, leguminosas e frutas, são facilmente disponíveis e, em geral, têm baixo custo. Não sofrem qualquer mudança no seu percurso pelo canal alimentar, pela inexistência de enzimas que as degradem (Tabela 1). O ideal é propor uma mistura que contenha um terço das chamadas fibras solúveis e dois terços das insolúveis, ambos modelos que atuam na mesma finalidade de oferecer resíduos e água para a formação de um bolo fecal de bom volume. Pela dieta ou por suplementação, a quantidade diária ideal de fibras encontra-se em torno de 30 a 35 g.

\begin{tabular}{lll} 
Tabela 1 & Fibras dietéticas & \\
Fibras & Tipo & Fontes principais \\
Solúveis & Pectinas & Frutas, leguminosas, aveia, cevada \\
& Gomas & \\
\hline Insolúveis & Celulose & Trigo, grãos, hortaliças \\
& Hemicelulose & \\
& Lignina & \\
& Mucilagens & \\
\hline
\end{tabular}




\section{Medidas comportamentais}

Os pacientes com tendência para constipação vão perdendo progressivamente o reflexo da evacuação. Nesses casos, aconselha-se ao próprio paciente identificar, de acordo com sua vontade e disponibilidade, qual é a hora que lhe pareça mais apropriada para disciplinar o aparecimento do reflexo, com a condição de poder cumpri-la todos os dias, sem a concorrência de outros compromissos previsíveis. Tempo e dedicação para o ato da evacuação são duas grandes colaborações do paciente para o sucesso dessa reeducação. O reaparecimento do reflexo e seu cumprimento são um grande passo para a normalização do esvaziamento intestinal. A postura assumida para evacuar deverá ser sugerida pelo médico. Outra recomendação refere-se à atividade física. Embora controversa, na prática se observa que o aumento da atividade física, talvez pelo exercício muscular da parede abdominal, é acompanhada de maior regularidade defecatória.

Finalmente, trocas ou suspensão, se possível, de medicamentos com interferência negativa sobre a motricidade enterocolônica devem ser abordadas com cuidado, mas fazem parte das propostas de estimular a solução da constipação, no conjunto geral da terapêutica clínica.

\section{Medicamentos}

Excetuando as fibras naturais ou sintéticas, não há dúvidas de que os laxantes agem de forma imediata na constipação, podendo, com ou sem efeitos colaterais, provocar evacuações diarreicas e satisfatórias para a maioria dos pacientes, motivo que justifica a elevada taxa de automedicação.

O tratamento da constipação é encarado, em geral, pelos pacientes como um ato simples de prescrição de uma droga e só procuram aconselhamento médico após uso espontâneo, prolongado e abusivo de laxativos.

O mercado farmacêutico brasileiro dispõe de vários laxantes (Tabela 2). Cada um desses grupos tem características farmacológicas distintas, alguns mais inócuos que outros, com indicações que precisam ser criteriosamente analisadas para que seu objetivo mais amplo seja alcançado. Certos produtos comerciais associam diferentes modelos de drogas, com finalidade de potencializar seus efeitos.

\section{Laxantes aumentadores de volume ou agentes hidrofílicos}

São fibras alimentares ou medicinais que promovem o aumento de peso, volume e fluidez das fezes que, durante sua passagem pelo cólon, estimulam 
Tabela 2 Classificação dos laxantes

\begin{tabular}{|c|c|}
\hline Agentes hidrofilicos (aumentadores de massa) & $\begin{array}{l}\text { Fibras dietéticas } \\
\text { Psyllium (Plantago ovata) } \\
\text { Metilcelulose } \\
\text { Policarbofila }\end{array}$ \\
\hline Agentes osmóticos (minerais) & $\begin{array}{l}\text { Sulfato, hidróxido ou citrato de } \mathrm{Mg} \\
\text { Sulfato ou fosfato de } \mathrm{Na}\end{array}$ \\
\hline Agentes osmóticos (açúcares) & $\begin{array}{l}\text { Lactulose, sorbitol, manitol } \\
\text { Polietilenoglicol }\end{array}$ \\
\hline Agentes emolientes/lubrificantes & $\begin{array}{l}\text { Docusatos } \\
\text { Óleo mineral } \\
\text { Glicerina }\end{array}$ \\
\hline Agentes estimulantes (difenilmetano) & $\begin{array}{l}\text { Fenolftaleína } \\
\text { Bisacodil }\end{array}$ \\
\hline Agentes estimulantes (antraquinona) & $\begin{array}{l}\text { Cáscara sagrada } \\
\text { Sene }\end{array}$ \\
\hline Agentes neuromusculares (colinérgicos) & Prostigmine ${ }^{\circledR}$ \\
\hline Agentes neuromusculares (agonistas $5 \mathrm{HT}_{4}$ ) & $\begin{array}{l}\text { Prucaloprida } \\
\text { Tegaserode }\end{array}$ \\
\hline Agentes neuromusculares (agonistas prostaglandinas) & Misoprostol \\
\hline Agonistas neuromusculares (?) & Colchicina \\
\hline
\end{tabular}

o incremento da flora bacteriana, resultando em bolo fecal maior. Interagem com a água por capacidade em retê-la nas fezes, na dependência de sua habilidade em superar os mecanismos da sua absorção no intestino delgado e cólon e escapar do metabolismo bacteriano colônico. $\mathrm{O}$ aumento de volume do conteúdo luminar ocorre por maior quantidade de material sólido retido durante o trânsito intestinal e obrigatoriamente de água, o que favorece a motricidade desses segmentos que, associada ao peso das fezes, acelera sua expulsão. Além do efeito motor, a consistência do bolo fecal, mais hidratado, também é reduzida por esses agentes, tornando sua eliminação facilitada. Os laxantes que atuam como aumentadores de massa são os que procuram se aproximar o máximo possível dos mecanismos fisiológicos da evacuação. Existem no farelo de cereais, ágar-ágar, celulose e no Psyllium (Plantago ovata) e em produtos sintéticos à base de metilcelulose, carboximetilcelulose e policarbofila.

A eficácia laxativa desses agentes depende da sua quantidade que permanece inalterada no intestino e, dessa forma, exerce sua atividade hidrofílica e a produção de produtos fermentados que se formam pela ação da flora do cólon. Somente se beneficiam dessa suplementação os pacientes cuja constipação não seja decorrente de trânsito lento ou obstrução da saída. 


\section{Laxantes osmóticos}

São drogas não absorvíveis que exercem importante efeito osmótico, promovendo retenção de água na luz intestinal. A intensidade dessa retenção, que se reflete no efeito laxante, será proporcional à quantidade de moléculas ou íons presentes durante seu trânsito. Dependendo da sua propriedade hipertônica, tendem a deslocar água já incorporada pelo organismo de volta para a luz do intestino. Assim, são potencialmente desidratantes. Estão representados por substâncias minerais, sulfatos, fosfatos e citratos de sódio e magnésio e hidróxido de magnésio, e açucaradas, como lactulose, sorbitol e manitol, além da glicerina e do polietilenoglicol. Os doentes com insuficiência renal utilizando produtos à base de magnésio, devem ser acompanhados com cautela, pois sua absorção em quantidade significativa concorre para quadros de intoxicação.

O polietilenoglicol tem vantagem sobre os outros quanto ao risco de desidratação. Não é metabolizado e não modifica o $\mathrm{pH}$ nem a flora bacteriana do cólon. Em prazo longo, em indivíduos idosos, mostrou eficácia significativamente maior que a lactulose e não interferiu em parâmetros nutricionais ou de absorção, considerados relacionados com esse tipo de medicamento. Igualmente, em crianças com constipação funcional crônica, apresentou ótimos resultados, sem efeitos adversos. Atualmente, por meio de um consenso, concluiu-se ser o laxativo de escolha para a constipação em grávidas, um grupo que tem limitações para indicação de medicamentos em geral. É a droga preferida para constipações refratárias e não é acompanhada de diarreia ou incontinência.

\section{Laxantes amaciantes}

Os laxantes amaciantes ou emolientes atuam como surfactantes, com a propriedade de facilitar a interface entre os componentes hidrofílicos e hidrofóbicos da massa fecal. Citam-se nesse modelo os óleos minerais e o ducosato de sódio, cálcio e potássio. Os ducosatos provocam um aumento na secreção de sódio, cloro e água pela mucosa cecal, motivo pelo qual são recomendados para uso de curta duração. Os óleos minerais têm função lubrificante. Se aspirados para a via respiratória, o que não é difícil em crianças e idosos, ocasionam pneumonias gordurosas de certa gravidade. Seu emprego prolongado pode contribuir para a má absorção de vitaminas lipossolúveis.

\section{Laxantes estimulantes, irritantes ou catárticos}

Os chamados laxantes estimulantes são fartamente consumidos pelos doentes tanto por prescrição médica quanto por, principalmente, automedi- 
cação. Compõem dois grandes grupos de drogas: derivados do difenilmetano e da antraquinona.

Os derivados do difenilmetano (fenolftaleína, bisacodil e oxifenizatina) inibem a absorção de sódio e glicose, aumentando o teor de água do cólon e estimulando sua motilidade. A utilização da fenolftaleína, pelos efeitos indesejáveis que provoca, está proibida no Brasil. O bisacodil tem absorção intestinal menor, mas é um irritante gástrico.

Os produtos contendo antraquinona (cáscara sagrada, sene, ruibarbo etc.) provocam maior secreção de água e eletrólitos pelo íleo distal e cólon, também estimulando as terminações nervosas, via plexo de Auerbach, gerando aumento na motricidade do intestino grosso. Problemas com essas estruturas podem ocorrer afetando sua sensibilidade, até de forma permanente, pelo uso prolongado desses laxantes. Estão associados com o aparecimento da melanosis coli, pigmentação benigna da mucosa colônica facilmente identificável em simples retoscopia, bem como com atrofia da musculatura lisa e do plexo mioentérico. Há vários produtos comerciais compostos com derivados da antraquinona, puros ou associados com outras drogas laxativas. Originados de plantas têm como parceiros dessa classe o óleo de rícino e o dantron. Esse caráter natural lhe confere certa credibilidade por parte dos usuários, que desconhecem seus efeitos secundários irreversíveis.

\section{Procinéticos}

Por sua ação sobre a atividade motora do tubo digestivo, teoricamente, são medicamentos com indicação interessante na constipação intestinal. Os procinéticos, recomendados inicialmente para a correção da dismotilidade de esôfago e estômago, não se mostraram tão eficazes para a regularização dos movimentos intestinais. Domperidona, bromoprida e metoclopramida não convenceram como agentes procinéticos intestinais.

Agonistas do receptor $5 \mathrm{HT}_{4}$ da serotonina, como o tegaserode, embora eficazes na constipação, não são prescritos rotineiramente por suas reações adversas no sistema cardiovascular. A prucaloprida, outro procinético com ação altamente seletiva ao receptor $5 \mathrm{HT}_{4}$, disponível no Brasil desde 2012, tem se mostrado muito eficaz no tratamento de mulheres com constipação funcional refratária aos tratamentos convencionais. Apresenta mínimo risco de efeitos colaterais, em especial cardíacos, e pode ser usada com segurança em idosos.

\section{Outros medicamentos com ação laxativa}

A eritromicina e a colchicina são drogas originalmente não pertencentes ao grupo dos laxantes. Embora demonstradas como úteis no tratamento de for- 
mas refratárias de constipação crônica, ainda não se situam entre os esquemas preferidos pelos especialistas, talvez por necessitarem de estudos com maior número de doentes e/ou por seus efeitos colaterais. A colchicina tem se mostrado eficaz em constipações refratárias, aumentando o número de evacuações com diminuição do tempo de trânsito, mas sua prescrição deve ser rigorosamente avaliada.

\section{Medicamentos tópicos}

Tratamentos tópicos são sempre considerados emergenciais e sua aplicabilidade de rotina será decidida em situações excepcionais, portanto, para uma parcela mínima de constipados. Evitá-los é a melhor conduta, embora em idosos possa ser a única forma de estímulo para evacuação.

\section{Biofeedback}

O procedimento mais difundido para casos de anismo diz respeito ao treinamento da musculatura perineal, por meio da técnica do biofeedback. Tem demonstrando resultados positivos, principalmente no anismo.

\section{TRATAMENTO CIRÚRGICO}

Cirurgias para resolução da constipação grave, afastadas as causas de evacuação obstruída, são de indicação excepcional e, por isso, exigem rigorosa seleção dos doentes. Correções de defeitos anatômicos, como lesões intraluminares, megacólons, prolapsos, enteroceles, intussuscepções etc., também merecem análises individualizadas sobre sua indicação cirúrgica. Fogem dessa conduta, obviamente, os casos de constipação secundária decorrentes de estenoses de qualquer natureza.

O algoritmo sugerido para as diversas etapas do diagnóstico e tratamento da constipação intestinal encontra-se na Figura 1. 


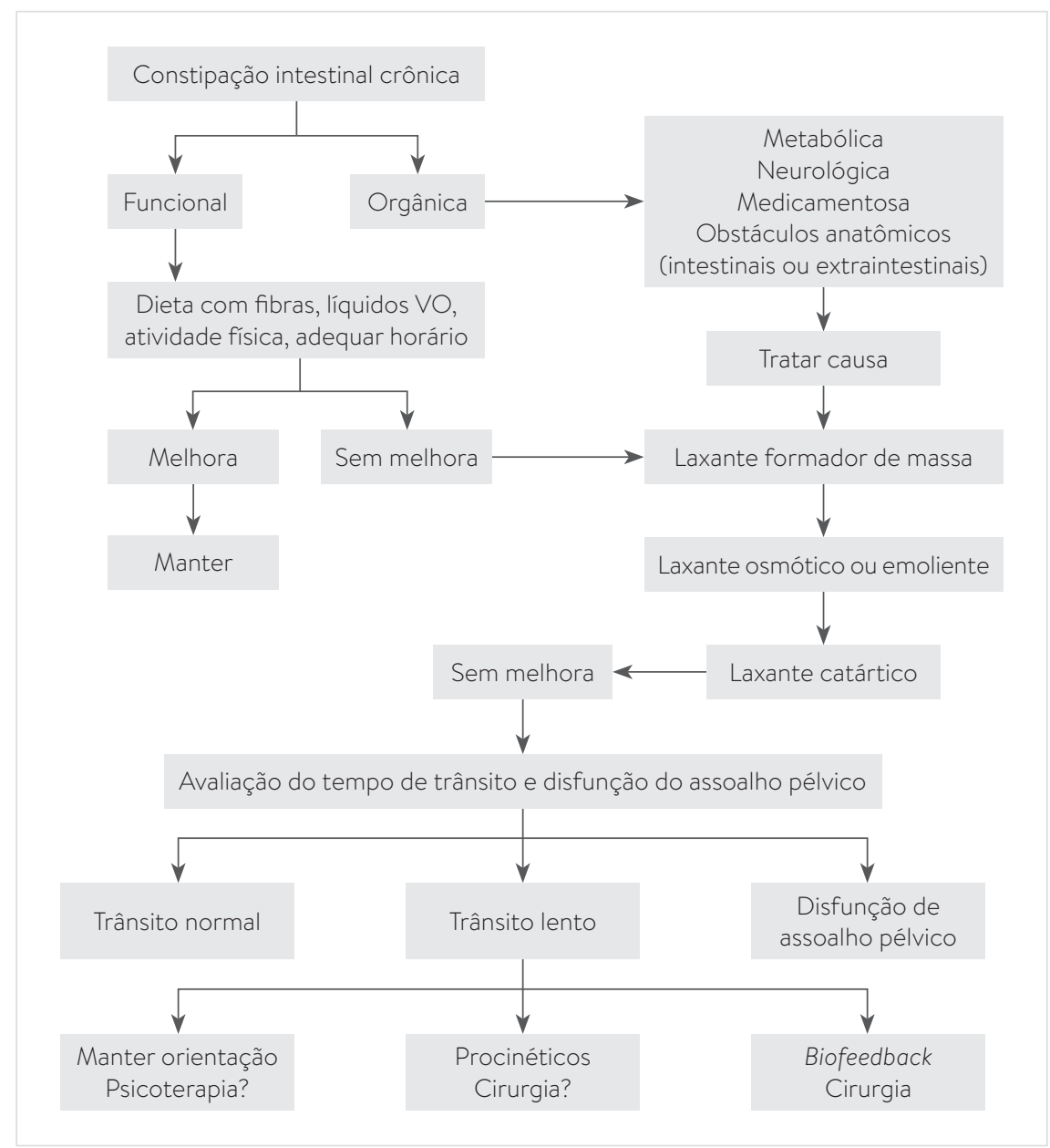

Figura 1 Algoritmo: diagnóstico e tratamento da constipação intestinal.

VO: via oral.

\section{REFERÊNCIAS BIBLIOGRÁFICAS}

1. Arce DA, Ermocilla CA, Costa H. Evaluation of constipation. Am Fam Physician. 2002;65:2283-90.

2. Baig MK, Zhao RH, Woodhouse SL, et al. Variability in serotonin and enterochromaffin cells in patients with colonic inertia and idiopathic diarrhea as compared to normal controls. Colorectal Dis. 2002;4:348-54.

3. Bellomo-Brandão MA, Collares EF, da Costa-Pinto EA. Use of erythromycin for the treatment of severe chronic constipation in children. Braz J Med Biol Res. 2003;36:1391-6.

4. Bordeianou L, Savitt L, Dursun A. Measurements of pelvic floor dyssynergia: which test result matters? Dis Colon Rectum. 2011;54(1):60-5.

5. Bouras EP, Tangalos EG. Chronic constipation in the elderly. Gastroenterol Clin N Am. 2009;38:463-80. 
6. Chang L, Toner BB, Fukudo S, et al. Gender, age, society, culture, and the patient's perspective in the functional gastrointestinal disorders. Gastroenterology. 2006;130(5):1435-46.

7. Chassagne P, Feuvrier G, Souliac B, Eoche R, Garnier P, Mathiex-Fortunet H, et al. Tolerance of long term administration of Macrogol 4000 (PEG 4000) in elderly patient suffering from chronic constipation. Gut. 2003;52(SupplVI)A223.

8. Chiarioni G, Whitehead WE, Pezza V, et al. Biofeedback is superior to laxatives for normal transit constipation due to pelvic floor dyssynergia. Gastroenterology. 2006;130(3):657-64

9. Coremans G, Kerstens R, De Pauw M, Stevens M. Prucalopride is effective in patients with severe chronic constipation in whom laxatives fail to provide adequate relief. Results of a double-blind, placebo-controlled clinical trial. Digestion. 2003;67:82-9.

10. D’Hoore A, Penninckx F. Obstructed defecation. Colorectal Dis. 2003;5:280-7.

11. Heymen S, Jones KR, Scarlett Y, Whitehead WE. Biofeedback treatment of constipation: a critical review. Dis Colon Rectum. 2003;46:1208-17.

12. Irvine EJ, Ferrazzi S, Pare P, Thompson WG, Rance L. Health-related quality of life in functional GI disorders: focus on constipation and resource utilization. Am J Gastroenterol. 2002;97:1986-93.

13. Johanson JF, Kralstein J. Chronic constipation. Aliment Pharmacol Ther. 2007; 25(5):599-608.

14. Kamm MA. Constipation and its management. BMJ. 2003;327:459-60.

15. Longstreth GF, Thompson WG, Chey WD, et al. Functional bowel disorders. Gastroenterology. 2006;130(5):1480-91.

16. Lyford GL, He CL, Soffer E, Hull TL, Strong SA, Senagore AJ, et al. Pan-colonic decrease in interstitial cells of Cajal in patients with slow transit constipation. Gut. 2002;51:496-501.

17. Muller-Lissner AS, Kamm MA, Sacrpignato C, et al. Myths and misconception about chronic constipation. Am J Gastroenterol. 2005;100:232-42.

18. Nylund G, Oresland T, Fasth S, et al. Long-term outcome after colectomy in severe idiopathic constipation. Colorectal Dis. 2001;3:253-8.

19. Peppas G, Alexiu VG. Epidemiology of constipation in Europe and Oceania: a systematic review. BMC Gastroenterol. 2008;8:5-12.

20. Quilici FA, Miszputen SJ, Quilici LCM. Constipação intestinal. In: Regadas FSP, Regadas SMM. Distúrbios funcionais. Rio de Janeiro: Revinter; 2007. p.198-202.

21. Quilici FA, Miszputen SJ, Quilici LCM. Constipação intestinal. In: São Paulo: FBG; 2012.

22. Raahave D, Loud FB, Christensen E, et al. Colectomy for refractory constipation. Scand J Gastroenterol. 2010;45(5):592-602.

23. Roberts MC, Millikan RC, Gaianko JA, et al. Constipation, laxative use, and colon cancer in a North Carolina population. Am J Gastroenterol. 2003;98:857-64.

24. Schiller LR. Review article: the therapy of constipation. Aliment Pharmacol Ther. 2001;15:749-63.

25. Talley NJ, Jones M, Nuyts G, et al. Risk factors for chronic constipation based on general practice sample. Am J Gastroenterol. 2003;98:1107-11.

26. Tariq SH. Constipation in long-term care. J Am Med Dir Assoc. 2007;8(4):209-18.

27. Tomita R, Igarashi S, Fujisaki S, et al. Significance of defecography in the diagnosis and evaluation of male patients with defecation disorders. Hepatogastroenterology. 2010;57(98):220-3.

28. Tytgat GN, Heading RC, Muller-Lissner S, et al. Contemporary understanding and management of reflux and constipation in the general population and pregnancy: a consensus meeting. Aliment Pharmacol Ther. 2003;18:291-301.

29. Van Outryve SM, Van Outryve MJ, De Winter BY, et al. Is anorectal endosonography valuable in dyschesia? Gut. 2002;5:695-700.

30. Verne GN, Davis RH, Robinson ME, et al. Treatment of chronic constipation with colchicine: randomized, double-blind, placebo-controlled, crossover trial. Am J Gastroenterol. 2003;98:1112-6.

31. Wofford SA, Verne N. Approach to patients with refractory constipation. Curr Gastroenterol Reports. 2000;2:389-94. 